\title{
eSports Evolution in Football Game Series
}

Authors' contribution:

A) conception and design of the study

B) acquisition of data

C) analysis and interpretation of data

D) manuscript preparation

E) obtaining funding

\section{Kacper Zagała ${ }^{\text {A-C }}$, Artur Strzelecki ${ }^{\text {C-E }}$}

University of Economics in Katowice, Katowice, Poland

Sport used to be practiced and watched only live. Over time, it started to be broadcast by the radio or television. The development of sport on the Internet has led to the emergence of eSports and professionalization of virtual sports competitions. For some gamers playing computer games has turned into competition and later into the professionalization of the game. This paper explores the topic of electronic sports and virtual competition. It discusses eSports and the accompanying behaviors and practices. Authors delivered taxonomy of video game types, game modes and current phenomenon of both online and land-based tournaments as well eSports leagues. The paper also illustrates how gamers are preparing themselves for tournaments and a crucial role of gamers' motivation. Authors present the FIFA football games series and its eSports application. The adopted research method allowed to obtain answers from $\mathrm{n}=452$ gamers. Results show that $60 \%$ of gamers have been spending more than 7 hours a week playing games. More than half of gamers have been playing for more than ten years. Most players play in games because it is considered as a hobby. Most of the gamers consider eSports as a sport. Most of the players are also spectators, who had watched in streaming at least one eSports tournament We find that FIFA game series has an extensive eSports platform and filled the gap by exploring it. Gamers usually play 40 games each weekend in FIFA eSports league but casual eSports gamers and spectators rarely take part in land-based tournaments.

eSports, football game series, video games, FIFA, gamers

\section{Introduction}

eSports, also known as electronic sport, is a form of competition between players in video games (Hamari \& Keronen, 2017). The definition characterizes eSports as a form of competition (both professional and amateur) in video games, most often coordinated by special leagues, lists and tables, and tournaments in which players play in teams (or individually) or other organizations sponsored by specific business entities (Hamari \& Sjöblom, 2017).

eSports is one of the fastest growing industries and attracts more and more visitors every year, both players and organizations that see it as a potential for their own growth (Adamus, 2012). The development of the whole gaming industry may be confirmed by the number of players. While in 1995 there were 100 million players, in 2018 we are talking about 2.36 billion players (Newzoo, 2018b). In 2014, there were 390 million eSports spectators (Newzoo, 2018a), 215 million of whom were not playing, but only watching. 
The goal of this paper is to explore aspects of behavior and motivation of eSports gamers in football game series. In literature, there are studies about the eSports behavior of gamers playing other games. However, this study is the first attempt to study eSports gamers in the example of FIFA game series. There are three key points to be learned from this study. First is the experience and motivation of gamers playing video games. Second is an eSports recognition among studied group. Third is an eSports application in FIFA game series.

The paper is organized as follows. Section 2 contains a taxonomy of video games and game modes. In this section we also introduce to eSports leagues and to FIFA game series. Section 3 includes the research method and hypotheses development, while section 4 presents the data and quantitative results. In section 5, the authors highlight the contribution of the research, discuss its limitations and, finally, draw conclusions about the results and propose possible future research avenues.

\section{eSports taxonomy}

This section contains taxonomy of video game types, game modes, tournaments and eSports leagues and football game series. Authors provide this taxonomy to show how eSports evolved from computer games. We understand eSports as evolution from computer games and games type to tournaments and eSports leagues. First, we describe popular video game types and game modes. Then we explore area of tournaments and eSports league, which base on different games and game modes. We choose FIFA game series, to show extensive application of tournaments and eSports leagues on this example.

\section{Video games types}

Fighting games are a video game genre based around interpersonal contact between characters controlled by players or by computer (artificial intelligence). They fight until they defeat their opponents, or the time expires. The game usually takes the form of a fist duel, but the player characters can also have weapons or use special skills (Lu et al., 2013). First-Person Shooter (FPS) games, as the name suggests, allow a player to play a role and see the game from the first-person perspective - the player experiences the action through the eyes of the protagonist. The player does not see his whole character on the screen but only his or her character's hands that hold a weapon or other object (Curley, Nausha, Slocum, \& Lombardi, 2016).

Real-Time Strategy (RTS) game is a form of strategy game. In such games, the player practices his ability to think analytically and make the right decisions to achieve his goals (Buro \& Churchill, 2012). The RTS games are not turn-based, as opposed to most of strategic games, which means that each player can move independently of the opponent. In RTS games there are only two players participating in the duel and control the whole game on the screen. Very similar game genre is Multiplayer Online Battle Arena (MOBA), however, the difference is that more players take part in the game and each of them controls one character who competes versus another team of players (Georgen, 2015).

Sports video games genre is a fairly wide category of games, which includes many types of games. One of them are sport simulators, such as football and basketball simulators (Anderson \& Carnagey, 2009). Another type of sports game are sport management games, for example the management of a football club (Kretschmann, 2012). There are also sports games which are highly unrealistic, use unrealistic graphical scale or simplified physics for ease of play, like for example, car races in special vehicles in the game called Need for Speed. Sports games are produced either for computers (mainly sport management games) or for game consoles (simulators). 


\section{Game modes}

Offline mode means that the player does not need to be connected to the Internet to play the game. Most often there is an offline campaign or a game story available, for example war campaign in Call of Duty game series or Manager Career mode in FIFA.

The online mode allows players to play over the Internet with people from all over the world. Online gaming is possible with servers. The location of servers usually depends on the region, for example in the League of Legends the servers are available from Western Europe and North America (Donaldson, 2017). A common problem with Internet gaming is lag, i.e. delays caused, for example, by a poor Internet connection. In addition, during an online game play it is not always possible to catch players who cheat, the so-called cheaters (Carter \& Gibbs, 2013).

LAN mode, i.e. in the local Internet network. The pattern of play is practically the same as in online gaming, but with one major difference - all players have to be connected to the same network. LAN is especially popular in the biggest eSports tournaments (Witkowski, 2012). They are organized in such a way that players meet in the venue of the tournament and compete with each other on previously prepared computer stations which eliminates the possibility of cheating.

The spectator mode is one that allows to watch the game, not play it (Karhulahti, 2016). The observation can be carried out from the perspective of one of the players or from different sites on the map, giving the spectators a more thorough experience. This mode is a particularly popular solution for eSports tournaments. Players see the game on their screens from their own perspective and the viewers watch it on separate screens from all different angles.

\section{Tournaments and eSports leagues}

eSports tournaments are usually held live with the participation of the spectators, referees or official representatives who ensure that players do not cheat. In the case of large tournaments in which there is a longer elimination process sometimes the tournaments are conducted online, and the winners of the qualifiers move to the finals.

The largest tournaments, such as Dreamhack, World Cyber Games, Major League Gaming Tournament or Intel Extreme Masters, are projects focused not only on the players but also on the audience (Jenny et al., 2018). These events highly resemble sporting contests (Heere, 2018; Holden, Kaburakis, \& Rodenberg, 2017). Participants need to get a ticket to get in, and the spectators are seated in the auditorium, in front of which there is a stage with player positions. Their progress in the game is displayed on large monitors, most often in the spectator mode which allows for a complex game play experience (Lee \& Schoenstedt, 2011). Usually such tournaments last many hours, sometimes even several days. Therefore, in addition to following the game itself, the fans can participate in various side events like competitions or mini-tournaments organized by the sponsors, they can spend time in entertainment zones or grab a bite in catering section. The fans who are not able to enter the tournament in person also have the possibility to watch the tournament (Hilvert-Bruce, Neill, Sjöblom, \& Hamari, 2018) as such events are often streamed live on YouTube or Twitch internet platforms (Sjöblom \& Hamari, 2017).

Playing for victory and recognition is very important for most players (Brown, Billings, Murphy, \& Puesan, 2018). In addition, the winner, or a high position holder, either an individual player or a whole team, is rewarded with a money prize. The larger the tournament and the more sponsors involved, the higher the prizes. The stakes are raising with the growing interest in virtual sport, which attracts more and more people (Davidovici-Nora \& Myriam, 2017). The prize pool for the Dota 2 International 2017 tournament was as much as $\$ 24$ million. In 2012 , the same tournament had a prize pool of $\$ 10.9$ million (Drachen et al., 2014). The business potential of electronic sports has attracted many sponsors, who often co-finance the tournament prizes (Block et al., 2018). 
They also take advantage of the presence of many computer game enthusiasts who naturally become prospective buyers of their products. That is why numerous stalls of companies that are somehow related to a given tournament or eSports event can be found at the venues where the tournaments are held. Most often they are companies producing computer hardware or software, but also companies from the energy drinks sector, for example.

Apart from annual tournaments which last for a limited period of time, eSports leagues are also popular. They usually take the form of a regular sports league, where all the players play a match against each other within a league, and the results are recorded in tables (Hallmann \& Giel, 2018). The American soccer league, the Major League Soccer (MLS), is a good example of that. Competition on a real football pitch is accompanied by the competition taking place on virtual stadiums. The MLS authorities came up with the idea that each team should put up its own player to compete for a virtual championship in the eMLS league (https://www.mlssoccer.com/eSports/emls/2018). Subsequent league events and matches are often streamed live to fans via online platforms such as Twitch.

The approach towards electronic sport began to change together with its development (Martoncik, 2015; Seo, 2016). Something that used to be merely entertainment started to become a way of life (Macey \& Hamari, 2018; Salo, 2017). The players started to unite (Reer \& Krämer, 2018) and put together their first teams. Shortly, experts and organizations joined in and started to form professional teams (Karhulahti, 2017) initially limited to a specific game, and later for many games on different platforms (Funk, Pizzo, \& Baker, 2018).

The players' task is to prepare themselves for the competition as well as they can and to achieve the highest possible final result (Drachen et al., 2014). They train for several hours a day (Bányai, Griffiths, Király, \& Demetrovics, 2019). In addition to developing their in-game skills and collaboration with other teammates, and there is a strong emphasis on tactics and mental preparation for the competitions (Kari \& Karhulahti, 2016; Ruvalcaba, Shulze, Kim, Berzenski, \& Otten, 2018). This is supervised by the professional experts, like coaches, who analyze the game of the opponents, watch the tactics at the tournaments, and tell the players what their next move should be (Lipovaya et al., 2018). A common practice in the case of multi-person teams is sharing an apartment. The players live and spend their time together so that they can reach a higher level of communication outside the virtual world (Stokes \& Williams, 2018). What is especially important in the eSports process are people responsible for the organization and management of the team and sponsors. The sponsors support the players, hoping for their victory, which they hope will also translate into the economic success of their enterprises (Hope, 2014). Most often, the sponsors of the teams are computer hardware and software companies (Seo, 2013). They provide their players with equipment of the highest possible quality so that the participants can best prepare for the tournament game playing. It is not uncommon that the players also receive a monthly salary or financial bonuses for good results (Brock, 2017).

\section{Football game series}

The two series Pro Evolution Soccer (PES) and FIFA (named after the Fédération Internationale de Football Association) are immediately considered when referring to football games or football simulators. These games that have completely dominated the virtual football market and are often presented as competitors. Each series has its own faithful fans who praise it while pointing out faults in the second game. PES supporters use an expanded tactical side and a real-life behavior on a virtual pitch as an argument for the superiority of this game play experience (Kayali \& Purgathofer, 2008), while FIFA players see the greatest advantages in the licenses the game holds, which allow the players to use original names or club costumes, so that the game uncannily resembles the real football matches. An advantage of the PES series was its license to reproduce the UEFA Champions League, but it was taken over by FIFA and it will be available starting from FIFA 19 series. 
FIFA is a sports video game which has been released every year since 1993. FIFA is a football simulator and its name is derived directly from the name of the World Football Federation - FIFA. The publisher of the game is Electronic Arts. FIFA is a football simulator of choice for a great number of players because of its realism (Stein, Mitgutsch, \& Consalvo, 2013). The game uses advanced technology, so that the game play and appearance of the players are very similar to real football matches (Markovits \& Green, 2017). An additional advantage of FIFA games series is having original licenses to use real club names, costumes, coats of arms, or player names.

As the next FIFA games were being created, the game modes available for players within a given series changed, too. In the first releases, single player modes dominated. Over time, with the development of technology and the Internet, more attention has been paid to multiplayer modes (Heckmann \& Furini, 2018). In FIFA18, one can play as many as eleven game modes. FIFA Ultimate Team is the most popular mode in the FIFA game series. It belongs to the online mode category, i.e. it requires an Internet connection. Each player creates their own club, under their own name, and chooses outfits for the virtual players, the stadium and the team from all the players available in the game.

The FUT Champions is a mode within the Ultimate Team in which a player qualifies for a special online league to be played during the weekend. The qualification takes the form of a tournament in which the player has to win four consecutive matches to secure a place in the weekend league. He uses for this purpose his players from the Ultimate Team. Usually before the weekend league the player can qualify for one of the two tournaments held, in both of which he can have a few attempts. After winning the tournament, the player gets a pass to the weekend league. In the FIFA18 edition the weekend league lasts from Friday to Sunday, in the FIFA17 edition it was only Saturday and Sunday. During one weekend, the players' task is to play up to 40 matches with other qualified players. The more wins there are, the higher the place in the weekly and monthly ranking. The ranking includes award levels determined by the number of wins in a given weekend league. FUT Champions rewards are the most impressive of all in the Ultimate Team, which is why this mode is very popular with the players.

The FUT Champions have had a significant impact on playing the tournaments to gain the best FIFA player in the world. Until this mode came out, local tournaments and qualifiers were organized to select a group of best players. The weekly and monthly rankings mentioned above have solved this problem. It is the game publisher who decides which months are designated for regional tournaments. This means that the top 64 players of the PS4 and the top 64 players of the Xbox One will take part in a regional tournament. These matches are held at a venue and not via the Internet. The matches are played in a special mode, created only for the purpose of the tournament. Having at their disposal all the players in the game the video game players select their teams, and the game takes place by means of a local LAN connection with a large screen to enable the audience to see the game.

Together with the development of the series and the release of new editions, the first attempts to organize tournaments for players began. Initially, they were small local tournaments, but with a growing interest in the series, the publishers started to think about larger, global tournaments. In 2004, the first edition of the FIFA Interactive World Cup took place. It can be described as the FIFA World Cup (Jenny, Manning, Keiper, \& Olrich, 2017). Since then, virtual football championships have been held every year and it is the most important tournament of the year for players (https://www.fifa.com/fifaeworldcup/index.html). The FUT Champions mode helped to organize the virtual championships, allowing for an efficient conduct of the first stages of the qualifying tournaments. The tournaments are held around the world and are live events with the participation of players and crowds of spectators. From each of the tournaments a certain number of players moves to the next round, and then they meet in the grand finale.

Apart from the biggest tournament, smaller competitions are still organized, both for professionals as well as for amateur players. Due to the fact that the eSports attracts more and more attention and interest from potential sponsors, sometimes they also organize competitions for the video game players. The competitions sometimes 
take the form of national championships (Parshakov \& Zavertiaeva, 2018). Often, along with the big tournaments or eSports events, tournaments for fans are also held. The winners are most often awarded computer equipment and accessories. Also, different store chains frequently organize tournaments, especially on the occasion of a new game series coming out. The winners are usually rewarded a new edition of a game.

\section{Research method and hypotheses development}

Although it has been around for some time now, eSports is a relatively new phenomenon which is only just beginning to attract attention. The issues discussed in this paper cannot be said to be definitely formed, solid and unchanging because the world of eSports is very dynamic and is constantly developing in various aspects. The subject of the present research is not limited only to eSports and its definition, but it also concerns the very subject of game playing. With all this in mind, the aim of this paper was to shed a light on what eSports is, and present certain notions and phenomena connected with it (Seo \& Jung, 2016). From among a variety of video games available on the market, the paper mostly describes football simulator - a series of FIFA games. The paper can be of interest to the players, both those who have had some experience with the series of FIFA games and those who are strangers to it. The purpose of the paper is to examine and present the characteristics of players - why they play and how often they do so, and whether apart from playing they watch eSports tournaments and try to be present in the virtual word, too. Additionally, the questions of whether the players are familiar with the concepts related to eSports, as well as various practices and aspects closely connected with it were examined in this paper.

Research questions (RQ) are as follows:

RQ1 Why, how long and how frequently do players play the games?

RQ2 Is the concept of eSports known to players and do they consider electronic sport to be a sport?

RQ3 Are players familiar with the FIFA football games series and its eSports application?

The first research question concerns the group under investigation, i.e. the video game players. To know the study group characteristics, it is necessary to obtain answers to questions related to the frequency of their playing, as well as the experience in game playing. Some subsequent opinions will depend on these factors. Players who play frequently and those who play sporadically see things differently (Nielsen \& Karhulahti, 2017). This question also concerns the motivation of players, that can help to understand why they play the games. For some of them, game playing is just for fun, for others it can be more than that. Some may combine game playing with emotions, while others perceive playing in a completely different way and approach it differently, too.

The second research question is designed to check how much players know about the concept of eSports. It is crucial to see whether they are familiar with the basic notions and aspects which are directly linked to electronic sport. The question also helps to examine players' opinions on how they perceive eSports in the context of other sports (Parry, 2019). Professional management, tournament streaming and wide media coverage all suggest that eSports should be taken seriously. It may be interesting to see if these factors, together with keen competition between players, make electronic sport a sport.

The third research question concerns the FIFA football series. It provides information on whether players are familiar with the whole series or with some of the individual games in the series. Additionally, the purpose of this question is to find out if the respondents play any specific editions, or maybe they are such keen enthusiasts of the game that they played all the editions that have been released. Verification of the general knowledge of the series precedes the second part of the question about how much the respondents know about the FIFA series eSports aspects. The question is, to find out whether the game players know about the tournaments that are being held, if they know the tournament players or maybe even the whole teams. It is also important to know whether the respondents participate in eSports activities such as single tournaments or entire events. 
Hypotheses made on the basis of these three research questions are going to be verified in a survey. On the basis of the first question concerning game players two hypotheses were formulated:

H1 Players have been playing for at least several years and spend at least a few hours a week playing.

$\mathrm{H} 2$ Players play because they consider it their hobby and they enjoy playing.

The second question concerns electronic sport and on its basis four hypotheses were proposed:

H3 Players are familiar with the concept of eSports and eSports-related aspects.

H4 Players consider eSports to be a sport.

H5 Players watched the Internet streaming of eSporst tournaments at least once.

H6 Players have participated live in an eSports tournament at least once.

The third question refers to a football game series and three hypotheses were made on this basis:

H7 Players are familiar with the FIFA game series.

H8 Players are familiar with the eSports context of the FIFA game series.

H9 Players are familiar with the latest edition of the FIFA18 series.

The introduction and methods are presented from the general aspects of playing, through eSports, through the FIFA series of football simulators. The next step is to formulate appropriate questions for the survey, which will be answered by the respondents. The questions concern eSports in its broadest sense, but they also focus on a specific example, i.e. a series of FIFA games. A more detailed part of the survey related to the FIFA series deals with issues related to the popularity of the game and its organization in eSports context. The survey participants were asked to fill in an online questionnaire on the subject of eSports, its context and, in a more detailed part of the survey, on FIFA game series.

Different perceptions of the same aspects of gaming and eSports develop perspectives for studying these phenomena. When analyzing the responses given, the previously formulated hypotheses are going to be compared with the feedback received from the studied group. It is important to check whether the proposed hypotheses are reflected in the opinions of the respondents, or, on the contrary, they should be rejected as not being in line with the answers obtained.

Questionnaire was distributed among fans of FIFA football game series and fans of football on Facebook. This certain group is connected with youtuber knows as xenq, who currently has a group on Facebook containing more than 8000 members. Questionnaire was posted with agreement of group administrator. The questionnaire consists of 31 closed-ended questions, most of which are in single-choice format with variants of answers provided. Several questions are in multiple-choice format and some have the option of adding the respondents' own answers. In addition, the questionnaire includes 3 open-ended questions, in which respondents were asked to enter their answers. The questionnaire also comprises a socio demographic section of five closed-ended questions where the respondents provided personal information about their age, sex, education, professional status, etc.

\section{Results}

In the part of the survey on game playing 441 respondents took part. They declared that they played games when asked the opening question of the survey. The respondents answered how long they had been playing, how often they had been playing on a weekly basis and why they played. Half of the players have been playing video games for over 10 years. The number of players who have been playing for several years now is also significant -199 respondents $(45 \%) .10$ respondents (2\%) have been playing for a few months, 6 persons have a year-long experience in game playing, and only 4 players admitted that they had started playing not long ago. The majority of respondents, as many as 99 (22\%), play more than 10 hours a week. A similar number of players 
- 92 respondents (21\%) play a few hours a day. Ranging from 7 to 10 hours a week there were 84 (19\%) respondents, from 4 to 6 hours a week -76 (17\%), and from 1 to 3 hours a week - 73 (less than 17\%). Only 17 people said they had been playing less than one hour a week, which translated into 4\%. 282 of the respondents treat playing as a hobby, and 227 people stated that it helped them to reduce stress levels. Other variants were not very common. Among the answers given by the respondents there were the following: 'I play professionally', 'I play because I like to compete', or 'I play because it is my partner's hobby'.

The part of the survey concerning eSports was done on 437 respondents who answered positively to the question whether they knew the concept of eSports. In this part of the survey the respondents defined what eSports is 206 people (47\%) said that it is an online multiplayer video game competition. $29 \%$ of players said that the best description of eSports would be that it is a kind of sport in which many people, not just players, are involved. Slightly more than $17 \%$ of the respondents said that eSports is a business. In the next step the respondents were asked to give one example of a game they associated with eSports and one example of an eSports team. As for games, Counter-Strike, and especially its latest version C-S: Global Offensive, was the game with the highest number of players. 157 respondents pointed this game. The name The League of Legends has also appeared frequently (indicated by 114 respondents). A significant number of respondents also indicated FIFA series as an example of an eSports game (there were 114 of them). As far as eSports teams are concerned, by far, most people (45\%) pointed to the Virtus.pro team, the main section of which is C-S: Global Offensive. Then the respondents answered the question whether they had ever participated in an eSports event. The vast majority, as many as $71 \%$, had never taken part in such an event. The remaining $29 \%$ participated in that kind of undertaking. The most frequently mentioned event was Intel Extreme Masters. Of the 437 people surveyed, $59 \%$ considered eSports to be a sport and the remaining $41 \%$ did not share this opinion. Of the 437 respondents, 314 (72\%) said they had watched some eSports game online and the remaining 123 persons (28\%) had not. As for the frequency of watching tournament online, among the people who watch it at all the declared frequency was 'occasionally' in about $34 \%$ of respondents, $18 \%$ of respondents watched it rarely, and $13 \%$ - often.

In the part of the survey concerning the FIFA football series took part 433 respondents who replied that they knew this game series. The next question was about having some experience with playing one of the games in the series. Here, too, almost everyone answered 'yes' - 420 people had played the games before, and 13 had not. Most people had played the games from FIFA11 to FIFA16 series, followed by the two latest releases, FIFA17 and FIFA18. The next question in this part of the survey commissioned was whether FIFA series could be described as an eSports game. 38\% of respondents rather agreed with the statement, and 34\% of players agreed entirely. The next questions were about the tournaments. When asked whether the respondents were familiar with FIFA series tournaments, $89 \%$ replied positively and $11 \%$ negatively. Two further questions checked whether the respondents were passive (just watching) or active (playing) participants in the tournaments. The question about following the online streaming of FIFA series tournaments was answered by 433 respondents. $35 \%$ of them watched tournaments occasionally, $17 \%$ frequently, and less than $6 \%$ watched regularly. Of all the respondents, less than $18 \%$ saw the tournament online once, and $25 \%$ did not watch tournaments at all. When asked about their participation in tournaments, whether online, such as national qualifiers, or land based, the respondents had a choice of 6 possible answers: 1) I play regularly (both online and land based), 2) I took part in a tournament several times, 3) I played in an online tournament once, 4) I played in a land based tournament once, 5) I participated as a spectator, 6) I never took part in a tournament. The responses given were as follows: more than half of the respondents never took part in a tournament and $10 \%$ participated in a tournament but only as spectators. As for the players $-17 \%$ took part several times, less than $5 \%$ played regularly, less than $10 \%$ participated in a land-based tournament once, and 5\% played an online tournament.

In the second section of the third part of the survey 401 participants confirmed that they knew FIFA18 game series, and 32 said that they did not know it. In percentage terms, less than $93 \%$ of respondents knew the game, and slightly more than $7 \%$ did not. Next, those who knew the game were asked to answer the question whether 
they had played it or not. $67 \%$ of the respondents admitted having played regularly, less than $16 \%$ said they had played it many times, and $8 \%$ had played it sporadically. $7 \%$ of respondents never played FIFA18. In the context of considering this football series as an eSports game, the Ultimate Team mode was the first choice. The respondents were asked if they knew this mode, especially the part FUT Champions (Weekend League). 33\% of respondents said that they regularly participated in the weekend league games, the same number of respondents said they had played this mode several times, and less than $19 \%$ admitted having played the Ultimate Team mode but excluding the FUT Champions. 13\% of respondents knew what it was but they never tried it, and $2 \%$ never heard of it.

\section{Discussion and conclusion}

The study provided answers to the research questions and allowed to verify the proposed hypotheses. In the first part, the research hypotheses concern gameplaying. The H1 hypothesis was positively verified. Most of the respondents have been spending more than 7 hours a week playing games for more than 10 years now. The $\mathrm{H} 2$ hypothesis was also corroborated, as the main factor influencing the players' gaming experience was that it was treated by them as a hobby (Martoncik, 2015).

In the second part of the study, the research hypotheses concern the perception of eSports. The H3 hypothesis was verified positively, as most of the respondents were able to list the eSports games most often played by players, and most of them knew the eSports teams that played in the tournaments. The H4 hypothesis was also positively verified, with most players considering eSports as a sport (McCutcheon, Hitchens, \& Drachen, 2018). The H5 hypothesis was also corroborated, as most of the respondents had watched the online streaming of the eSports games at least once. The H6 hypothesis, on the other hand, should be rejected, as most of the respondents had not participated live in eSports tournaments.

In the third part of the study, the research hypotheses refer to a series of football games. The H7 hypothesis was positively verified as most players were familiar with the FIFA football series. Also, the H8 hypothesis concerning the knowledge of the FIFA series eSports aspect was positively verified. Players knew the eSports modes of the game, but only a small percentage of them had participated in the game tournaments, and most of them had watched it streamed live online. The H9 hypothesis was also positively verified. Most players were familiar with the newest release of FIFA18.

eSports is a relatively new phenomenon. However, it already earned some considerable research attention worldwide. Our results are along with others. Gamers are playing more and more (Hamari \& Keronen, 2017; Martoncik, 2015; Seo \& Jung, 2016). Spectators are watching more and more of streamed tournaments (Hamari \& Sjöblom, 2017; Hilvert-Bruce et al., 2018; Macey \& Hamari, 2018; Sjöblom \& Hamari, 2017). Contribution of this paper is that the eSports environment of FIFA football game series is explored and extensive application of esports league in this game is shown.

Our results show that 59\% responses from questionnaire considered eSports as a sport. However, in the literature we can find two opposite point of views. One group of researchers consider eSports as a sport (Karsenti \& Bugmann, 2018; Pizzo et al., 2018; Rosell Llorens, 2017), as our results show, whereas second group of researchers have opposite results (Parry, 2019; Skubida, 2016; Willimczik, 2019).

The main limitation of the present study is that it was conducted among people who are interested in games and devote their time to game playing. If the same survey were conducted among a group that do not play sports video games, the responses about eSports could be completely different, but to confirm this thesis it would require a separate study. The second limitation of the present research is narrowing the examination of eSports to only one series of sports games. A broader perspective on eSports would certainly be provided by research based on other types of games that are popular with players. 
This paper deals with a broad and relatively new subject, which is eSport. The first part provides definitions of basic concepts such as eSports, and discusses elements related to it, such as game types, game modes, tournaments and eSports teams. An example of an eSports game, the FIFA Football Simulator series, is also illustrated. After the introduction and presentation of the methods applied, the results are presented.

Finding the answers to the research questions was the aim of this paper. Three research questions were related to aspects of game playing, eSports and a series of sports games. The data collected and the results of the survey enabled the authors of this paper to find answers to all of the research questions. The paper provides information on who plays video games, how long and how often they have been playing, as well as why they do it. It was also possible to find answers to questions concerning the perception of eSports in the context of a sport, certain aspects of electronic sport, as well as FIFA football series. On the basis of the research questions, hypotheses were formulated, the verification of which was sought in the research results. Out of nine hypotheses put forward, eight were confirmed by the results of the research. They concerned both game playing and eSport, but also a series of sports games.

The subject of this paper is very broad, and it can be said that it is only being discovered now. Every so often, new games and devices are created, new teams are formed, and new tournaments or events are run. The potential for research is, therefore, considerable. This paper may be treated as a pilot study of this phenomenon. It contains basic concepts and explains certain behaviors and practices present in eSport. However, the research area should be examined in greater depth. The direction of future research may be expanding this research by including other video games in it, not necessarily sports games, but games from other categories as well. The opinions of the players who play them may be interesting to note. They may have a completely different profile and experience in playing and have a different understanding of some aspects of game playing or eSports. There is also a great potential for research in undertaking the topic of the economic and business aspects of eSports. Therefore, the issues related to the value of eSports markets, cost-effectiveness of engaging in eSports or interest in electronic sports on the part of various business entities not directly related to it would be worth exploring.

\section{REFERENCES}

Adamus, T. (2012). Playing computer games as electronic sport: In search of a theoretical framework for a new research field. In J. Fromme \& A. Unger (Eds.), Computer Games and New Media Cultures (pp. 477-490). Dordrecht: Springer. https://doi.org/10.1007/978-94-007-2777-9_30

Anderson, C.A. \& Carnagey, N.L. (2009). Causal effects of violent sports video games on aggression: Is it competitiveness or violent content? Journal of Experimental Social Psychology, 45(4), 731-739. https://doi.org/10.1016/j.jesp.2009.04.019

Bányai, F., Griffiths, M.D., Király, O. \& Demetrovics, Z. (2019). The psychology of esports: A systematic literature review. Journal of Gambling Studies, 35(2), 351-365. https://doi.org/10.1007/s10899-018-9763-1

Block, F., Hodge, V., Hobson, S., Sephton, N., Devlin, S., Ursu, M.F., Cowling, P. I. (2018). Narrative bytes: Data-driven content production in esports. In Proceedings of the 2018 ACM International Conference on Interactive Experiences for TV and Online Video - TVX '18 (pp. 29-41). New York, NY: ACM Press. https://doi.org/10.1145/3210825.3210833

Brock, T. (2017). Roger Caillois and e-sports: On the problems of treating play as work. Games and Culture, 12(4), 321339. https://doi.org/10.1177/1555412016686878

Brown, K.A., Billings, A.C., Murphy, B., \& Puesan, L. (2018). Intersections of fandom in the age of interactive media: eSports fandom as a predictor of traditional sport fandom. Communication and Sport, 6(4), 418-435. https://doi.org/10.1177/2167479517727286

Buro, M. \& Churchill, D. (2012). Real-time strategy game competitions. AI Magazine, 33(3), 106. https://doi.org/10.1609/aimag.v33i3.2419

Carter, M. \& Gibbs, M. R. (2013). eSports in EVE Online: Skullduggery, fair play and acceptability in an unbounded competition. In Proceedings of Foundation of Digital Games - FDG'13 (pp. 47-54).

Curley, A., Nausha, M., Slocum, J. \& Lombardi, D. (2016). What motivates esports fans? A data-driven approach to business and development strategy. Southern Methodist University Guildhall. Retrieved from http://andrewcurley.net/s/Curley_ThesisPaper.pdf 
Davidovici-Nora, M. \& Myriam. (2017). e-Sport as leverage for growth strategy: The example of League of Legends. International Journal of Gaming and Computer-Mediated Simulations, 9(2), 33-46. https://doi.org/10.4018/IJGCMS.2017040103

Donaldson, S. (2017). Mechanics and metagame: Exploring binary expertise in League of Legends. Games and Culture, 12(5), 426-444. https://doi.org/10.1177/1555412015590063

Drachen, A., Yancey, M., Maguire, J., Chu, D., Wang, I. Y., Mahlmann, T., Klabajan, D. (2014). Skill-based differences in spatio-temporal team behaviour in defence of the Ancients 2 (DotA 2). In 2014 IEEE Games Media Entertainment (pp. 1-8). Toronto, ON, Canada: IEEE. https://doi.org/10.1109/GEM.2014.7048109

Funk, D.C., Pizzo, A.D. \& Baker, B.J. (2018). eSport management: Embracing eSport education and research opportunities. Sport Management Review, 21(1), 7-13. https://doi.org/10.1016/j.smr.2017.07.008

Georgen, C. (2015). Well played \& well watched: Dota 2, spectatorship, and eSports. Well Played A Journal on Video Games, Values, and Meaning, 4(1), 179-191.

Hallmann, K. \& Giel, T. (2018). eSports - Competitive sports or recreational activity? Sport Management Review, 21(1), 14-20. https://doi.org/10.1016/j.smr.2017.07.011

Hamari, J. \& Keronen, L. (2017). Why do people play games? A meta-analysis. International Journal of Information Management, 37(3), 125-141. https://doi.org/10.1016/j.ijinfomgt.2017.01.006

Hamari, J. \& Sjöblom, M. (2017). What is eSports and why do people watch it? Internet Research, 27(2), 211-232. https://doi.org/10.1108/IntR-04-2016-0085

Heckmann, P.L. \& Furini, L. (2018). The introduction of women's teams in FIFA 16 and how Brazilian women reacted to it. Estudos Em Comunicação, 1(26), 247-260. https://doi.org/10.20287/ec.n26.v1.a14

Heere, B. (2018). Embracing the sportification of society: Defining e-sports through a polymorphic view on sport. Sport Management Review, 21(1), 21-24. https://doi.org/10.1016/j.smr.2017.07.002

Hilvert-Bruce, Z., Neill, J. T., Sjöblom, M. \& Hamari, J. (2018). Social motivations of live-streaming viewer engagement on Twitch. Computers in Human Behavior, 84, 58-67. https://doi.org/10.1016/j.chb.2018.02.013

Holden, J., Kaburakis, A. \& Rodenberg, R.M. (2017). The future is now: Esports policy considerations and potential litigation. Journal of Legal Aspects of Sport, 27(1), 46-78. https://doi.org/10.1123/jlas.2016-0018

Hope, A. (2014). The evolution of the electronic sports entertainment industry and its popularity. Computers for Everyone, $1,87-89$.

Jenny, S.E., Keiper, M.C., Taylor, B.J., Williams, D.P., Gawrysiak, J., Manning, R.D. \& Tutka, P.M. (2018). eSports venues: A new sport business opportunity. Journal of Applied Sport Management, 10(1), 34-49. https://doi.org/10.18666/JASM-2018-V10-I1-8469

Jenny, S.E., Manning, R.D., Keiper, M.C. \& Olrich, T.W. (2017). Virtual(ly) athletes: Where eSports fit within the definition of "Sport." Quest, 69(1), 1-18. https://doi.org/10.1080/00336297.2016.1144517

Karhulahti, V.M. (2016). Prank, troll, gross and gore: Performance issues in Esport live-streaming. In 1st International Joint Conference of DiGRA and FDG (pp. 1-13). Dundee.

Karhulahti, V.M. (2017). Reconsidering esport: Economics and executive ownership. Physical Culture and Sport, Studies and Research, 74(1), 43-53. https://doi.org/10.1515/pcssr-2017-0010

Kari, T. \& Karhulahti, V.M. (2016). Do E-athletes move? : A study on training and physical exercise in elite E-Sports. International Journal of Gaming and Computer-Mediated Simulations, 8(4), 53-66. https://doi.org/10.4018/IJGCMS.2016100104

Karsenti, T. \& Bugmann, J. (2018). eSport: A new university sport? International Journal of Technologies in Higher Education, 15(1), 74-87. https://doi.org/10.18162/ritpu-2018-v15n1-07

Kayali, F. \& Purgathofer, P. (2008). Two halves of play - Simulation versus abstraction and transformation in sports videogames design. Eludamos. Journal for Computer Game Culture, 2(2), 105-127.

Kretschmann, R. (2012). Digital sport-management games and their contribution to prospective sport-managers' competence development. Advances in Physical Education, 2(4), 179-186. https://doi.org/10.4236/ape.2012.24031

Lee, D. \& Schoenstedt, L.J. (2011). Comparison of eSports and traditional sports consumption motives. ICHPER-SD Journal of Research, 6(2), 39-44.

Lipovaya, V., Lima, Y., Grillo, P., Barbosa, C E., de Souza, J.M. \& Duarte, F.J.de C.M. (2018). Coordination, communication, and competition in eSports: A comparative analysis of teams in two action games. In Proceedings of the 16th European Conference on Computer-Supported Cooperative Work - Exploratory Papers. European Society for Socially Embedded Technologies (EUSSET). https://doi.org/10.18420/ecscw2018_11 
Lu, F., Yamamoto, K., Nomura, L.H., Mizuno, S., Lee, Y. \& Thawonmas, R. (2013). Fighting game artificial intelligence competition platform. In Proc. of the 2nd IEEE Global Conference on Consumer Electronics (GCCE 2013) (pp. 320-323). Tokyo: IEEE. https://doi.org/10.1109/GCCE.2013.6664844

Macey, J. \& Hamari, J. (2018). Investigating relationships between video gaming, spectating esports, and gambling. Computers in Human Behavior, 80, 344-353. https://doi.org/10.1016/j.chb.2017.11.027

Markovits, A.S. \& Green, A.I. (2017). FIFA, the video game: a major vehicle for soccer's popularization in the United States. Sport in Society, 20(5-6), 716-734. https://doi.org/10.1080/17430437.2016.1158473

Martoncik, M. (2015). E-Sports: Playing just for fun or playing to satisfy life goals? Computers in Human Behavior, 48 , 208-211. https://doi.org/10.1016/j.chb.2015.01.056

McCutcheon, C., Hitchens, M. \& Drachen, A. (2018). eSport vs irlSport. In A. Cheok, M. Inami, \& T. Romão (Eds.), Lecture Notes in Computer Science (pp. 531-542). Champagne, IL: Springer. https://doi.org/10.1007/978-3-319-76270$8 \_36$

Newzoo. (2018a). Global eSports Market Report. Retrieved from https://newzoo.com/insights/trend-reports/globaleSports-market-report-2018-light/

Newzoo. (2018b). Global Games Market Report. Retrieved from https://newzoo.com/insights/trend-reports/newzooglobal-games-market-report-2018-light-version/

Nielsen, R.K.L. \& Karhulahti, V.-M. (2017). The problematic coexistence of "internet gaming disorder" and esports. In Proceedings of the International Conference on the Foundations of Digital Games - FDG '17 (pp. 1-4). New York, NY: ACM. https://doi.org/10.1145/3102071.3106359

Parry, J. (2019). E-sports are not sports. Sport, Ethics and Philosophy, 13(1), 3-18. https://doi.org/10.1080/17511321.2018.1489419

Parshakov, P. \& Zavertiaeva, M. (2018). Determinants of performance in eSports: A country-level analysis. International Journal of Sport Finance, 13(1), 34-51.

Pizzo, A.D., Baker, B.J., Na, S., Lee, M.A., Kim, D. \& Funk, D.C. (2018). eSport vs. Sport: A comparison of spectator motives. Sport Marketing Quarterly, 27(2), 108-123.

Reer, F. \& Krämer, N.C. (2018). Psychological need satisfaction and well-being in first-person shooter clans: Investigating underlying factors. Computers in Human Behavior, 84, 383-391. https://doi.org/10.1016/j.chb.2018.03.010

Rosell Llorens, M. (2017). eSport gaming: The rise of a new sports practice. Sport Ethics and Philosophy, 11(4), 464-476. https://doi.org/10.1080/17511321.2017.1318947

Ruvalcaba, O., Shulze, J., Kim, A., Berzenski, S.R., \& Otten, M.P. (2018). Women's experiences in esports: Gendered differences in peer and spectator feedback during competitive video game play. Journal of Sport and Social Issues, 42(4), 295-311. https://doi.org/10.1177/0193723518773287

Salo, M. (2017). Career transitions of esports athletes: A proposal for a research framework. International Journal of Gaming and Computer-Mediated Simulations, 9(2), 22-32. https://doi.org/10.4018/IJGCMS.2017040102

Seo, Y. (2013). Electronic sports: A new marketing landscape of the experience economy. Journal of Marketing Management, 29(13-14), 1542-1560. https://doi.org/10.1080/0267257X.2013.822906

Seo, Y. (2016). Professionalized consumption and identity transformations in the field of eSports. Journal of Business Research, 69(1), 264-272. https://doi.org/10.1016/J.JBUSRES.2015.07.039

Seo, Y. \& Jung, S.-U. (2016). Beyond solitary play in computer games: The social practices of eSports. Journal of Consumer Culture, 16(3), 635-655. https://doi.org/10.1177/1469540514553711

Sjöblom, M., \& Hamari, J. (2017). Why do people watch others play video games? An empirical study on the motivations of Twitch users. Computers in Human Behavior, 75, 985-996. https://doi.org/10.1016/j.chb.2016.10.019

Skubida, D. (2016). Can some computer games be a sport? Issues with legitimization of esport as a sporting activity. International Journal of Gaming and Computer-Mediated Simulations, $8(4, \quad 1, \quad$ SI), $38-52$. https://doi.org/10.4018/IJGCMS.2016100103

Stein, A., Mitgutsch, K. \& Consalvo, M. (2013). Who are sports gamers? A large scale study of sports video game players. Convergence: The International Journal of Research into New Media Technologies, 19(3), 345-363. https://doi.org/10.1177/1354856512459840

Stokes, B. \& Williams, D. (2018). Gamers who protest: Small-group play and social resources for civic action. Games and Culture, 13(4), 327-348. https://doi.org/10.1177/1555412015615770

Willimczik, K. (2019). eSport is not sport-eSport and sport have meanings. An analysis from the perspective of a philosophy of language instead of ontological debates. German Journal of Exercise and Sport Research, 49(1), 78-90. 
https://doi.org/10.1007/s12662-019-00569-2

Witkowski, E. (2012). On the digital playing field: How we "do sport" with networked computer games. Games and Culture, 7(5), 349-374. https://doi.org/10.1177/1555412012454222

\section{AUTHOR'S ADDRESS:}

Artur Strzelecki

Department of Informatics, University of Economics in Katowice,

1 Maja 50, 40-287 Katowice

Poland

E-mail: artur.strzelecki@ue.katowice.pl

Received: 24 August 2018; Accepted: 3 June 2019 